\title{
LVI. On the electrostatic dimensions of a magnetic pole
}

\section{Prof. J. Larmor}

To cite this article: Prof. J. Larmor (1882) LVI. On the electrostatic dimensions of a magnetic pole, Philosophical Magazine Series 5, 13:83, 429-430, DOI: $10.1080 / 14786448208627210$

To link to this article: http://dx.doi.org/10.1080/14786448208627210

曲 Published online: 28 Apr 2009.

Submit your article to this journal $ऍ$

Џ Article views: 7

Q View related articles $\sqsubset$ 
which they are placed; but, according to Maxwell, the magnetic force between a current and a magnetic pole does not. Hence the moment of the magnetic shell equivalent to a given current depends on the medium surrounding the shell. If the field be occupied by one medium only, the moment of the magnetic shell $=\mu$. current $\times$ area. This equation gives the dimensions $\mathrm{M}^{\frac{1}{2}} \mathrm{~L}^{\frac{1}{2}}$ for $m$.

The effect of the medium surrounding a current upon the magnetic force produced by the current has, as far as I know, not been investigated. The only experiments I know bearing on this point are some experiments of Faraday on the effect of the surrounding medium on the electric currents indnced by a moving magnet. The result of the experiments was, that he could not detect that changing the medium had any effect on the induced currents. If this be so, then Maxwell's statement must be right. For, imagine a long magnet in presence of an electric current, and let one pole be in one medium and the other in another; then, if the forces on the two poles are different in magnitude, we may carry the magnet round the current so as to get work out of it. Now this work must have come from the battery ; but, since the inductive action of the magnet on the current is independent of the medium, there will be on the whole no currents induced by the motion of the magnet: hence no work can come from the battery; hence the forces on the poles must be equal, or the magnetic force produced by a current must be independent of the surrounding medium. I may mention that Mr. E. B. Sargant, of 'Trinity College, is at present experimentally investigating this point. Mr. W. D. Niven has pointed out to me that the value given by Clausius for the dimensions of a magnetic pole does not make the magnetic force between two such poles of the dimensions of a force, which ought clearly to be the case.

$$
\begin{aligned}
& \text { I am, Gentlemen, } \\
& \text { Your obedient servant, } \\
& \text { J. J. THomson. }
\end{aligned}
$$

LVI. On the Electrostatic Dimensions of a Magnetic Pole. By Prof. J. Larmon*.

CIAAUSIUS's formula to connect the dimensions of current and pole on the static system, viz.

(A) Moment of Magnet = Current $\times$ Area,

seems really to involve the electromagnetic system of units. It is plain that, to be able to make and establish practically * Communicated by the Author.

Phil. May. S. 5. Vol. 13. No. 83. June 1882. $2 \mathrm{~K}$ 
such a relation as to the magnetic action of a current, we must assume tacitly these previous relations (which in fact supply our only mode of comparison and verification), viz.:-

(1) $(\text { Pole })^{2} \times \mathrm{L}^{-2}=$ Force,

(2) Current $\times \mathrm{L} \times$ Pole $\times \mathrm{L}^{-2}=$ Force.

The first of these is the purely magnetic starting-point of the electromagnetic system; and the second is the relation which must be used to connect current with pole on any systern. But the electrostatic system naturally starts with the dimensions of electric quantity as deduced from the law of inverse squares, whence those of current are deduced at once. Now, the only simple fact of nature which connects pole with current is Oersted's phenomenon (as developed by Amperre) of the existence of a mutual force between them : this is expressed by $(2)$; and hence by this relation must we deduce the dimensions of pole from those of current already found. The somewhat recondite fact that the magnetic action of a small circuit carrying a current may be represented as due to two fictitions magnetic poles, does not seem to possess any claims to strpplant the natural statement of the only fundamental relation which makes natural poles play a part in electric theory at all. That relation is, of course, itself in its very nature electromagnetic.

It might be said that the system objected to built up the theory from electric foundations, inasmuch as its fundamental magnet is a small electric current. But, in reply, it is the existence of actual magnets which introduces the idea of pole at all, other than as in Ampère's purely mathematical directrix of electrodynamic action; and the above considerations seem to show that this result is only obtained at the cost of preferring the fulfilment of the practically composite relation (A) to that of the fundamental electromagnetic relation (2), in the specification of an electrostatic system. This, though allowable if consistently adhered to, does not seem to be naturalif indeed the specification of a magnetic pole on an electrostatic system is a matter of importance at all.

The method indicated gives Maxwell's dimensions, $\mathrm{L}^{\frac{1}{2}} \mathrm{M}^{\frac{1}{2}}$.

In practice, one would most probably investigate the $d y$ namic relations of statical charges with a galvanometer, and not with an electrodynamometer.

Queen's College, Galway, May 10, 1862. 